\title{
PERANCANGAN APLIKASI ANDROID PENILAIAN KINERJA DAN SIKAP SPIRITUAL KARYAWAN (STUDI KASUS TOKO RETAIL IDOLMART)
}

\author{
Isa Faqihuddin Hanif ${ }^{1)}$ \\ ${ }^{1)}$ Universitas Prof. Dr. Hamka \\ Jl. Tanah Merdeka No.6, RT.10/RW.3, \\ Rambutan, Kec. Ps. Rebo, Kota Jakarta Timur, 13830 \\ Telp (021) 87782739 Fax - Mobile 0858-1300-1800 \\ Website: www.ft.uhamka.ac.id \\ E-mail: info@uhamka.ac.id
}

\begin{abstract}
Abstrak - Teknologi berbasiskan mobile dalam aktifitas perusahaan saat ini, merupakan hal yang perlu diterapkan guna mendapatkan efisiensi dari segi waktu, tanpa harus mengurangi komponen penting dari fungsi sebuah aktivitas perusahaan itu sendiri. Salah satu divisi yang perlu mendapatkan perhatian dalam pengembangan teknologi ialah divisi personalia, dikarenakan dalam mengelola kinerja dan sikap karyawan dalam skala banyak dan bersifat fluktuatif tersebut dibutuhkan sistem terintegrasi berbasis mobile yang userfriendly dan mampu mengefisiensikan penggunaan alat penilaian terhadap keseluruhan karyawan maupun jajaran direksi yang sebelumnya menggunakan sistem berbasis web. Divisi personalia Idolmart saat ini sedang menjalankan program dengan fokus penilaian kinerja karyawan, sistem yang sedang berjalan saat ini masih berbasis desktop yang akan dikembangkan menjadi aplikasi mobile berbasis android. Tujuan dalam pembuatan aplikasi ini ialah menemukan bukti empiris pengaruh positif terhadap efisiensi program penilaian karyawan divisi personalia Idolmart melalui aplikasi android. Jenis penelitian ini menggunakan penelitian kualitatif yang menekankan pada bagaimana bagian personalia Idolmart menggunakan program pengembangan diri melalui aplikasi android untuk menghasilkan penilaian kepribadian sehari hari karyawannya. Hasil dari penelitian ini adalah, output tampilan berupa laporan tabel dari semua hasil inputan menu yang diakses langsung oleh karyawan melalui aplikasi android dan dapat dilihat melalui menu view. Aplikasi android dapat digunakan oleh setiap karyawan Idolmart sesuai dengan perkembangan operasi sistem android yang akan datang.
\end{abstract}

Kata kunci: Sistem Informasi, Android, Aplikasi Mobile, Penilaian Karyawan, Retail.

\begin{abstract}
Mobile-based technology in the company's current activities, is something that needs to be applied in order to obtain efficiency in terms of time, without having to reduce the important components of the function of a company's activities itself. One division that needs attention in technology development is the personnel division because in managing the performance and attitudes of employees on a large scale and fluctuating nature, it requires an integrated system based on mobile that is userfriendly and able to efficiently use the appraisal tool for all employees and directors who previously used web-based system. The personnel division of Idolmart is currently running a program with a focus on employee performance appraisal, the system currently running is still desktop-based which will be developed into an Android-based mobile application. The purpose of making this application is to find empirical evidence of a positive influence on the efficiency of employee assessment programs for the Idolmart personnel division through the android application. This type of research uses qualitative research that emphasizes how the personnel section of Idolmart uses a self-development program through an android application to produce an assessment of the daily personality of its employees. The results of this study are, the output in the form of periodic table reports from all input menus can be accessed directly by employees through the android application via the view menu. The android
\end{abstract}


application can be used by every Idolmart employee in accordance with the development of the upcoming Android operating system.

Keywords: Information System, Android, Mobile Application, Employees Appraisement, Retail.

\section{PENDAHULUAN}

Teknologi berbasiskan mobile dalam aktifitas perusahaan saat ini, merupakan hal yang perlu diterapkan guna mendapatkan efisiensi dari segi waktu, tanpa harus mengurangi komponen penting dari fungsi sebuah aktivitas perusahaan itu sendiri. Salah satu divisi yang perlu mendapatkan perhatian dalam pengembangan teknologi ialah divisi personalia, Bidang personalia dapat dikatakan sebagai divisi dimana seluruh karyawan di manage dengan standarisasi aturan personalia agar terciptanya kondisi yang mendukung perusahaan dalam menjalankan aktifitasnya supaya berkembang. Dukungan ini tentunya tidak terlepas dari peran karyawan yang memposisikan dirinya sebagai sasaran tujuan bidang personalia demi kemajuan sumber daya manusia perusahaan. Dikarenakan dalam mengelola kinerja dan sikap karyawan dalam skala banyak dan bersifat fluktuatif tersebut maka dibutuhkan sistem terintegrasi berbasis mobile yang userfriendly dan mampu mengefisiensikan penggunaan alat penilaian terhadap keseluruhan karyawan maupun jajaran direksi yang sebelumnya menggunakan sistem penilaian berbasis web.

\section{LANDASAN TEORI}

\subsection{PERSONALIA DAN KARYAWAN}

Peran bidang personalia dalam sebuah perusahaan merupakan sebagai wadah dimana seluruh karyawan di manage dengan standarisasi aturan personalia agar terciptanya kondisi yang mendukung perusahaan dalam menjalankan aktifitasnya supaya berkembang. Dukungan ini tentunya tidak terlepas dari peran karyawan yang memposisikan dirinya sebagai sasaran tujuan bidang personalia demi kemajuan sumber daya manusia perusahaan. Manajemen personalia adalah perencanaan, pengembangan, pembagian kompensasi, penginterprestasian, dan pemeliharaan tenaga keraja dengan maksud untuk membantu mencapai tujuan perusahaan, individu dan masyarakat. (Ranupandojo dan Husnan, 2002). Karyawan adalah seseorang yang ditugaskan sebagai pekerja dari sebuah perusahaan untuk melakukan operasional pada perusahaan. Kedudukan karyawan dalam sebuah perusahaan sangatlah penting, oleh karena itu pengelolaan karyawan cukup penting karena akan mempengaruhi banyak aspek penentu keberhasilan kinerja perusahaan. Karyawan tentu erat kaitannya dengan kinerja, oleh karena itu, proses penilaian karyawan dirasa perlu dilakukan dalam suatu perusahaan, terutama dalam penentuan karyawan terbaik guna memberi motivasi dan penghargaan. Setiap perusahaan tentu memiliki cara yang berbeda-beda dalam menentukan karyawan terbaiknya, tergantung kebijakan manajemen perusahaan. (Ardy tri widiyanto, 2016)

\subsection{ANDROID}

Silvia (2001) menyatakan bahwa manfaat teknologi informasi baru dapat dirasakan jika pengguna teknologi informasi tersebut menyadari manfaatnya. Android adalah sistem operasi dengan sumber terbuka, dan Google merilis kodenya di bawah Lisensi Apache. Kode dengan sumber terbuka dan lisensi perizinan pada Android memungkinkan perangkat lunak untuk dimodifikasi secara bebas dan didistribusikan oleh para pembuat perangkat, operator nirkabel, dan pengembang aplikasi. Selain itu, Android memiliki sejumlah besar komunitas pengembang aplikasi (apps) yang memperluas fungsionalitas perangkat, umumnya ditulis dalam versi kustomisasi bahasa pemrograman Java. Android juga menjadi pilihan bagi perusahaan teknologi yang menginginkan sistem operasi berbiaya rendah, bisa dikustomisasi, dan ringan untuk perangkat berteknologi tinggi tanpa harus mengembangkannya dari awal. Sifat Android yang terbuka juga telah mendorong munculnya sejumlah besar komunitas pengembang aplikasi untuk menggunakan kode sumber terbuka sebagai dasar proyek pembuatan aplikasi, dengan menambahkan fitur-fitur baru bagi pengguna tingkat lanjut atau mengoperasikan Android pada perangkat yang secara resmi dirilis dengan menggunakan sistem operasi lain.

\subsection{TOKO RETAIL IDOLMART}

Idolmart merupakan salahsatu perusahaan yang berfokus pada penjualan retail yang sedang berkembang ditengah ketatnya persaingan dalam jual-beli kebutuhan sehari-hari berbasis mini market. Visi Idolmart "menjadi perusahaan retail nomor satu di asia yang akan memberikan kebahagian bagi karyawan / investor dan pelanggan". Misi Idolmart Memberikan pelayanan terbaik bagi pelanggan dengan produk yang unik,murah \& lengkap Memberikan kesejahteraan bagi semua karyawan Turut menggerakkan pertumbuhan ekonomi \& mengurangi tingkat pengangguran di Indonesia. Dengan budaya spritual, idolmart adalah sarana ibadah bagi semua orang yang terlibat didalamnya. Bidang personalia dalam Toko Retail Idolmart selalu mengembangkan kinerjanya sebagai bentuk profesionalitas terhadap fokus bisnis yang sedang dijalankannya. Salah satu bentuk pendukungnya, ialah melakukan evaluasi terhadap seluruh karyawannya secara berkala guna melihat perkembangan dari sisi kepribadian dan aktivitasnya, seperti membuat laporan keseharian mengenai sholatnya, membaca Al-Quran, membaca buku, dan aktifitas lainnya yang berkaitan dengan kepribadian. Dengan didukungnya evaluasi sumber daya manusia dan adanya transformasi dari sisi system informasi, membuat karyawan lebih mudah dalam mengerjakan sesuatu yang bersifat mobile seperti penggunaan gadget dalam melakukan aktifitasnya. Program yang sebelumnya sudah berjalan masih terkendala dengan 
keterbatasan dari sisi efisiensi waktu dan tempat, karena setiap user diharuskan menginput menggunakan computer dan membutuhkan waktu yang cukup lama, dan harus bergantian untuk melakukan penginputan dikarenakan kapasitas computer yang terbatas.

\section{METODOLOGI PENELITIAN}

\subsection{Skema Alur Penelitian}

Tabel 1 Alur Penelitian

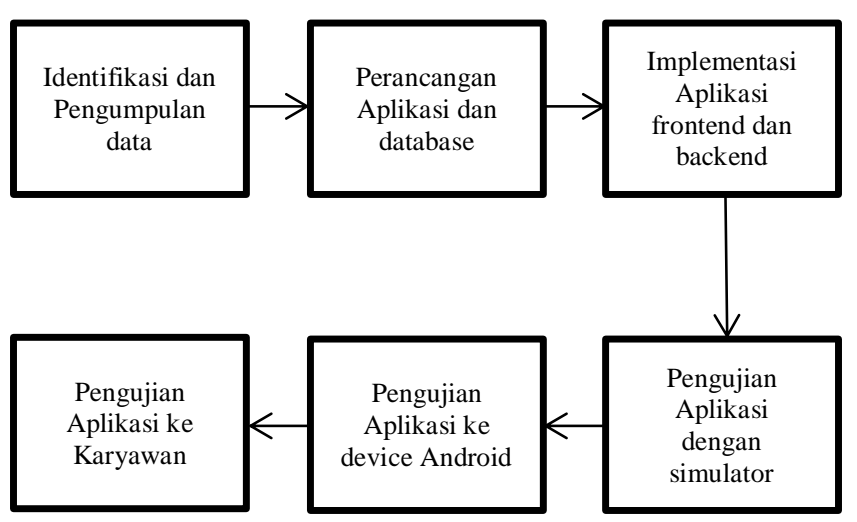

3.1.1 Identifikasi Masalah

Melakukan perumusan masalah yang akan diteliti. Pada Toko Retail Idolmart tengah dijalankan program penilaian karyawan dengan memanfaatkan teknologi informasi yaitu dengan aplikasi berbasis desktop. Namun efisiensi dalam melakukan pengisian data masih belum maksimal, karena data yang perlu diisi masih harus diinput melalui komputer.

\subsubsection{Menyusun Desain Perancangan}

Pembuatan skema alur kerja aplikasi android penilaian aktivitas karyawan. Pada tahap ini merupakan langkah membuat gambar tampilan menu dan relasi setiap menu yang akan dijadikan sebagai bahan pembuatan aplikasi. Menu utama terdiri dari 6 (enam) menu, yaitu menu riyadoh, menu baca buku, menu baca Al-Quran, menu view, menu about dan menu karyawan. Untuk menu riyadoh, menu baca buku, menu baca Al-Quran, dan menu karyawan mempunyai relasi ke menu view, dikarenakan hasil input akan didistribusikan ke dalam database dan akan ditampilkan ke dalam menu view.

\subsubsection{Pembuatan Aplikasi}

Memulai menerapkan hasil desain perancangan sesuai dengan menggunakan analisa kebutuhan perangkat. Dalam pembuatan aplikasi ini berfokus kepada software eclipse, dimulai dengan pembuatan tampilan splahscreen serta pembuatan menu utama dan pemilihan icon button. Setelah itu pembuatan sub sub menu dan merelasikan setiap menu yang terdapat pada menu utama ke dalam database. Dan terakhir pembuatan output dalam bentuk format pdf.

\subsubsection{Pengujian Aplikasi}

Membuat kesimpulan mengenai hasil dari tahap pembuatan aplikasi, dengan menguji semua variabel yang telah dijelaskan pada tahap identifikasi penamaan variabel. Pengujian ini meliputi, fungsi text field untuk penginputan data setiap menu, keakuratan hasil nilai, dan data output dalam bentuk pdf, serta uji coba setiap button yang terdapat disetiap menu.

\subsection{Jenis Dan Teknik Pengumpulan Data}

Jenis penelitian ini adalah penelitian kualitatif yang menekankan pada bagaimana bagian personalia Toko Retail Idolmart menggunakan sistem pengembangan diri untuk menghasilkan penilaian kepribadian sehari hari terhadap karyawannya. Data penelitian ini menggunakan data sekunder, Data sekunder didapatkan dari hasil pembuatan aplikasi pengembangan diri bidang personalia Toko Retail Idolmart yang disajikan dalam bentuk output program. Dalam pengumpulan data, peneliti melakukan wawancara kepada bagian IT dan HRD Toko Retail Idolmart serta perancangan alur untuk nantinya di implementasikan pada tahap pembuatan program dan beberapa fitur yang dapat difungsikan sebagaimana mestinya yang nanti akan dijabarkan melalui screenshot serta penjelasannya. Dalam penelitian ini, penulis juga menggunakan software eclipse dalam melakukan pembuatan program, dan menggunakan database mysql sebagai penyimpanan database dari hasil input melalui aplikasi android.

\section{HASIL DAN PEMBAHASAN}

Pengembangan progam penilaian kinerja karyawan Toko Retail Idolmart divisi personalia yang sebelumnya menggunakan desktop dalam mengoperasikannya menjadi aplikasi berbasis android, penulis menyertakan hasil berupa tampilan dan output dari aplikasi. Didalam aplikasi terdapat 6 menu pada halaman utama yang akan dijabarkan, seperti menu riyadoh, menu baca buku, menu baca Al-Quran, menu view, menu about dan menu master data. Didalam menu riyadoh, berisi inputan berupa pengisian jadwal sholat dan aktivitas sehari-hari, dalam menu baca buku berisi inputan berupa judul buku yang dibaca, menu baca Al-Quran berisi inputan surat yang telah dibaca dan jumlah ayat yang dibaca, menu view berisikan output dari menu riyadoh, menu baca buku dan menu baca Al-Quran. Menu master data berisi inputan untuk data karyawan dalam perusahaan.

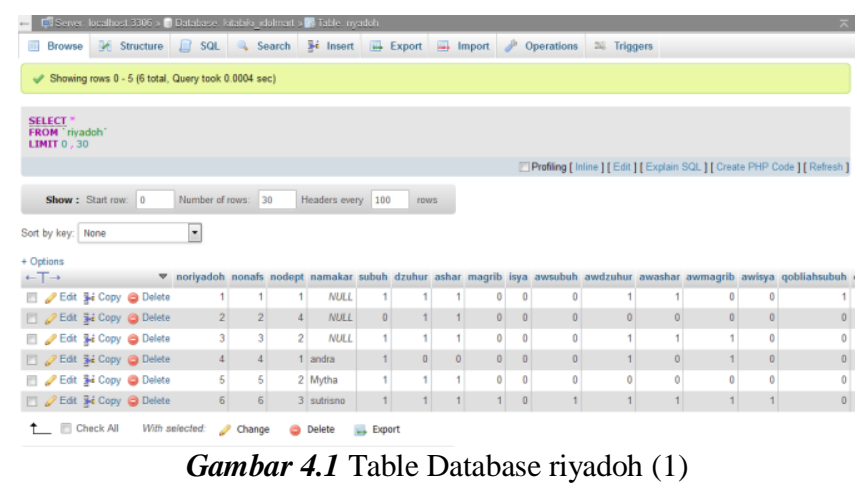



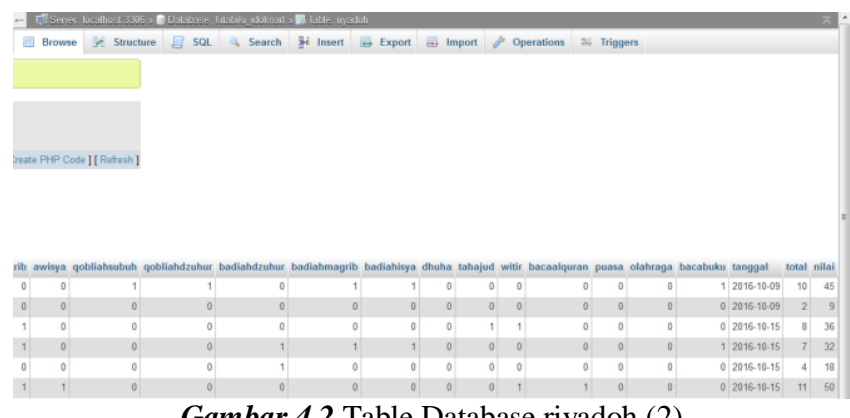

Gambar 4.2 Table Database riyadoh (2)

Tabel database dari menu riyadoh yang berisikan field-field yang nantinya digunakan untuk menyimpan hasil ouput yang diinput melalui aplikasi android. Field nokar, nodept, dan namakar merupakan field standart yang terdapat pada setiap table database, karena digunakan untuk menyimpan setiap identitas karyawan. Terdapat 22 point yang dijadikan sebagai penilaian, yakni sholat subuh, dzuhur, ashar, maghrib, isya, awSubuh, awdzuhur, awashar, awmaghrib, awisya, qobliahsubuh, qobliahdzuhur, badiahdzuhur, badiahmaghrib, badiahisya, dhuha, tahajud, witir, bacaalquran, puasa, olahraga, bacabuku.

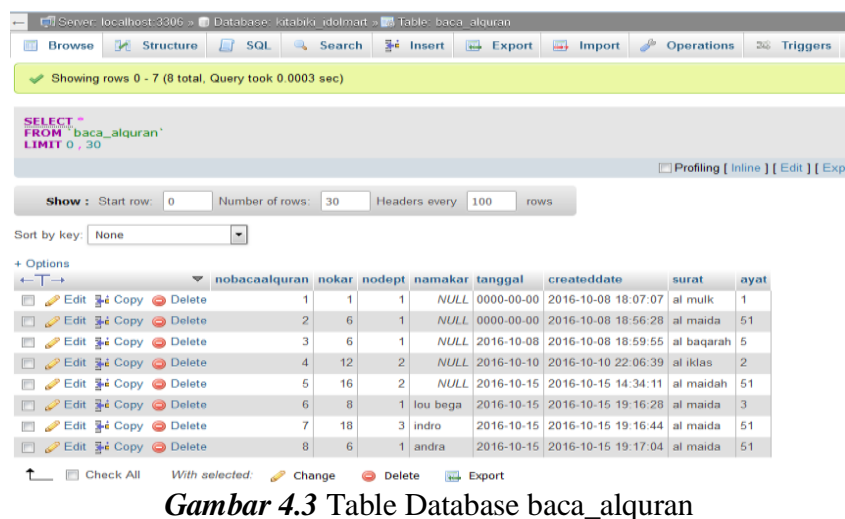

Database dari menu baca Al-Quran, yang berisikan fieldfield yang nantinya digunakan untuk menyimpan hasil ouput yang diinput melalui aplikasi android. Field nokar, nodept, dan namakar merupakan field standart yang terdapat pada setiap table database, karena digunakan untuk menyimpan setiap identitas karyawan. Terdapat 2 point yang dijadikan sebagai penilaian, yakni nama surat yang dibaca dan jumlah ayat yang dibaca.

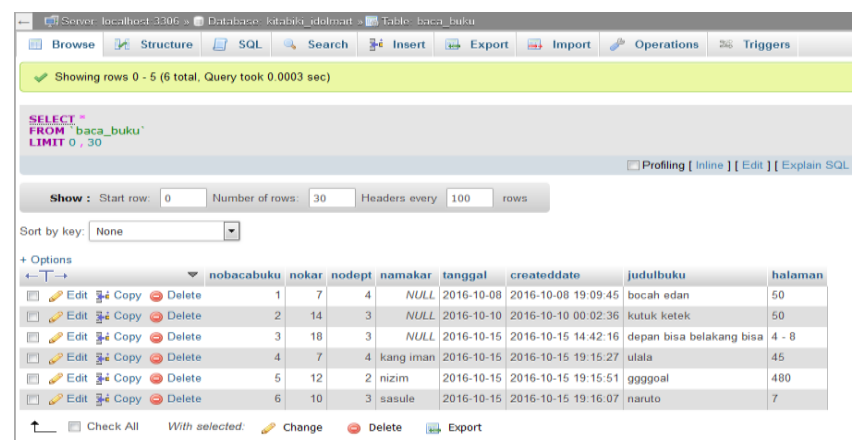

Gambar 4.4 Table Database baca_buku
Database dari menu baca buku, yang berisikan field-field yang nantinya digunakan untuk menyimpan hasil ouput yang diinput melalui aplikasi android. Field nokar, nodept, dan namakar merupakan field standart yang terdapat pada setiap table database, karena digunakan untuk menyimpan setiap identitas karyawan. Terdapat 2 point yang dijadikan sebagai penilaian, yakni nama buku yang dibaca dan jumlah halaman yang dibaca.

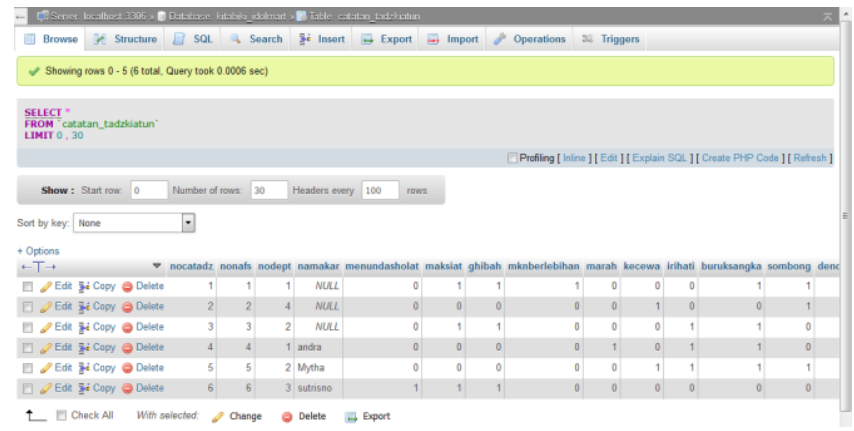

Gambar 4.5 Table Database catatan_tadzkiatun (1)

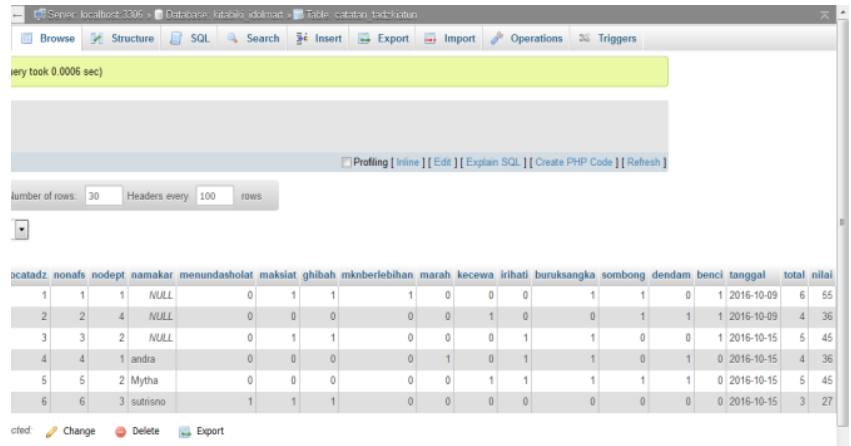

Gambar 4.6 Table Database catatan_tadzkiatun (2)

Database dari menu catatan_tadzkiatun, yang berisikan fieldfield yang nantinya digunakan untuk menyimpan hasil ouput yang diinput melalui aplikasi android. Field nokar, nodept, dan namakar merupakan field standart yang terdapat pada setiap table database, karena digunakan untuk menyimpan setiap identitas karyawan. Terdapat 11 point yang dijadikan sebagai penilaian, yakni menunda sholat, maksiat, ghibah, makan berlebihan, marah, kecewa, irihati, buruksangka, sombong dendam, benci.

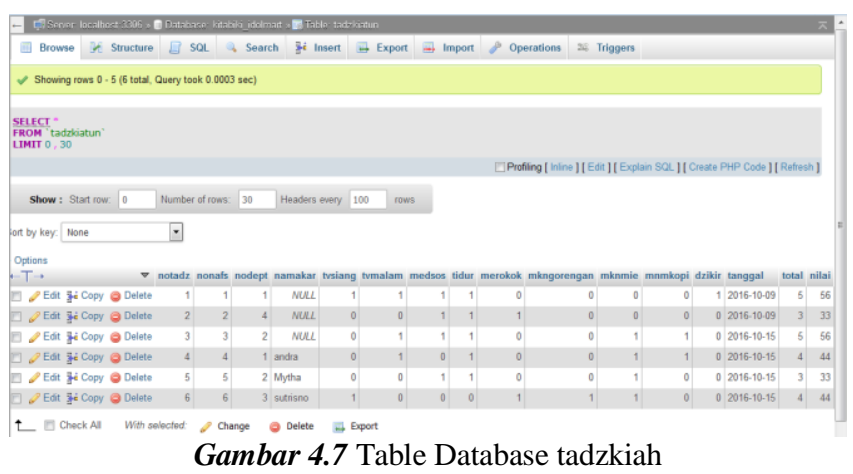

Database dari menu tadzkiah, yang berisikan field-field yang nantinya digunakan untuk menyimpan hasil ouput yang diinput melalui aplikasi android. Field nokar, nodept, dan namakar merupakan field standart yang terdapat pada setiap 
table database, karena digunakan untuk menyimpan setiap identitas karyawan. Terdapat 9 point yang dijadikan sebagai penilaian, yakni nonton tv siang, nonton tv malam, media sosial, tidur, merokok, makan gorengan, makan mie, makan kopi, dzikir.

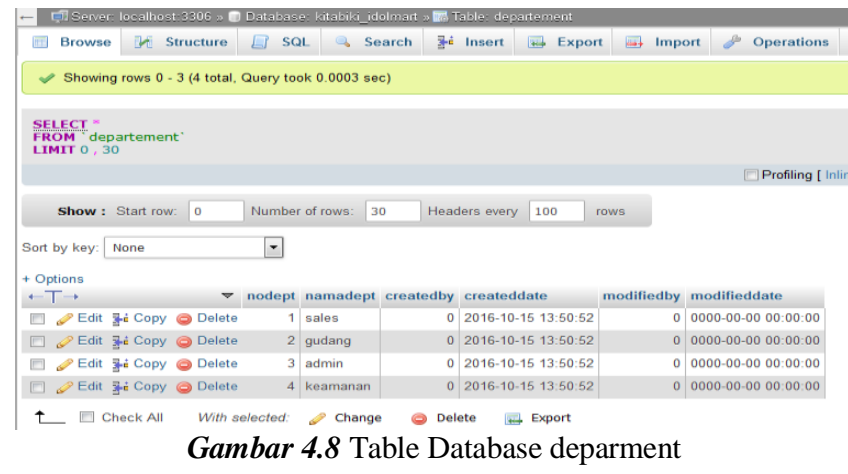

Database dari menu master departement, yang berisikan field-field yang nantinya digunakan untuk menyimpan hasil ouput yang diinput melalui aplikasi android. Field nokar, nodept, merupakan field standart yang terdapat pada table database departement, karena digunakan untuk menyimpan setiap identitas karyawan. Terdapat 1 point yang dijadikan sebagai inputan, yaitu nama department.

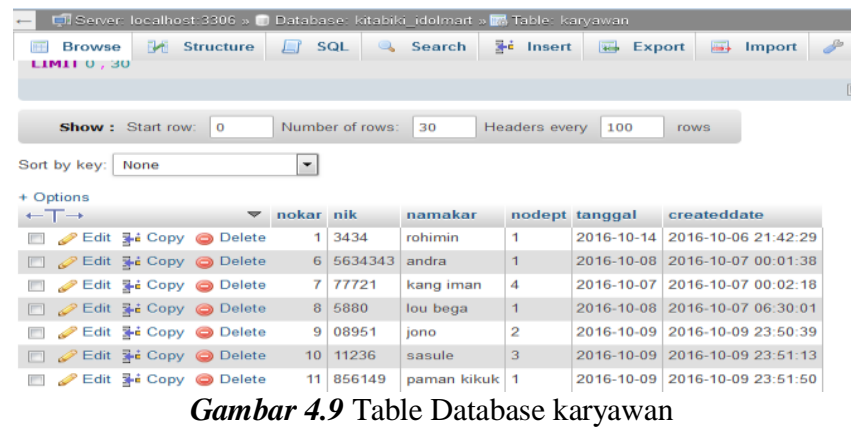

Database dari menu master karyawan, yang berisikan fieldfield yang nantinya digunakan untuk menyimpan hasil ouput yang diinput melalui aplikasi android. Field nokar, nodept, nik dan namakar merupakan field standart yang terdapat pada table database karyawan, karena digunakan untuk menyimpan setiap identitas karyawan. Terdapat 3 point yang dijadikan sebagai inputan, yaitu nomor induk karyawan, nama karyawan, dan nama department.

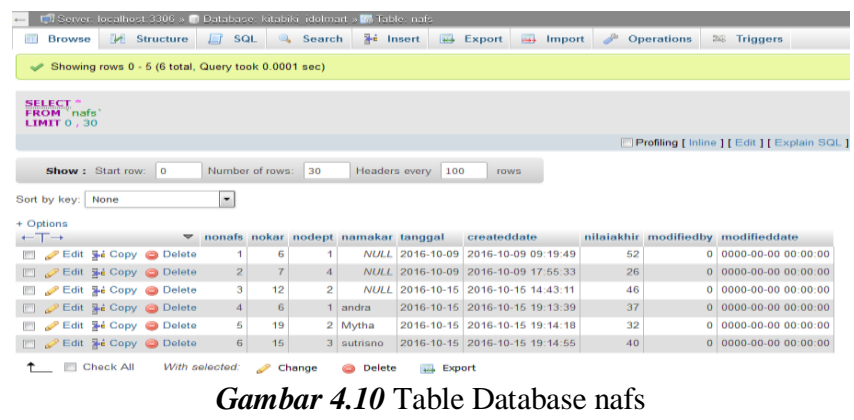

Database dari menu master karyawan, yang berisikan fieldfield yang nantinya digunakan untuk menyimpan hasil semua ouput yang diinput pada menu utama aplikasi android.
Field nokar, nodept, dan namakar merupakan field standart yang terdapat pada setiap table database, karena digunakan untuk menyimpan setiap identitas karyawan. Terdapat 3 point yang dijadikan sebagai inputan, yaitu nomor induk karyawan, nama karyawan, dan nama department.

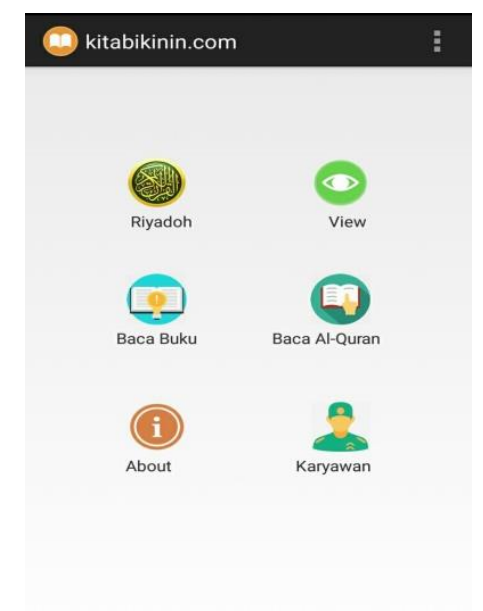

Gambar 4.11 Tampilan utama aplikasi

merupakan menu utama aplikasi. Halaman utama diatas berisikan 6 menu. Menu riyadoh berisi inputan jadwal sholat, menu view berisikan output keseluruhan pada menu input halaman utama, menu baca buku berisikan inputan mengenai buku apa saja yang telah dibaca, menu baca Al-Quran berisikan inputan mengenai surat dan ayat yang telah dibaca, menu about berisikan cara penggunaan aplikasi, dan menu master karyawan berisikan inputan nama, nik, dan dept. karyawan.

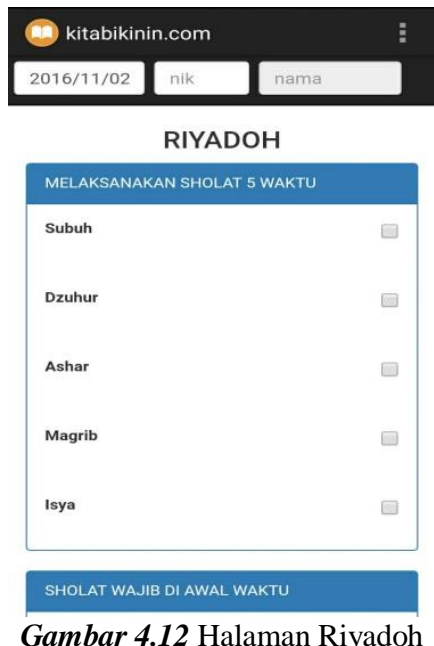

Kolom date akan diisi sesuai tanggal input pengisian, kolom nik diisi sesuai dengan nik karyawan, setelah kolom nik diisi otomatis kolom name akan terisi dengan sendirinya sesuai dengan nik karyawan. Kolom jadwal sholat, diisi dengan di klik sesuai dengan kotak kecil yang tersedia. Kolom total nilai akan menampilkan nilai keseluruhan dari inputan jadwal sholat dan lainnya. Lalu tombol submit akan mengirim data kedalam database. 


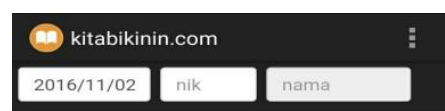

Baca Al-Quran

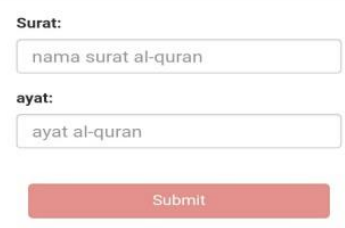

Gambar 4.13 Halaman Baca Al-Quran

Kolom date akan diisi sesuai tanggal input pengisian, kolom nik diisi sesuai dengan nik karyawan, setelah kolom nik diisi otomatis kolom name akan terisi dengan sendirinya sesuai dengan nik karyawan. Pengisian surat sesuai dengan nama surat yang dibaca dan pengisian ayat sesuai dengan jumlah ayat yang dibaca. Setelah itu klik tombol submit untuk pendistribusian data kedalam database.

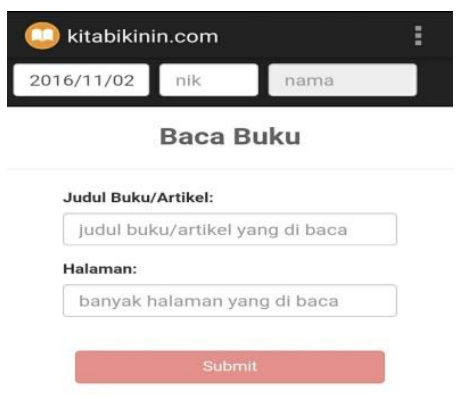

Gambar 4.14 Halaman Baca Buku

Kolom date akan diisi sesuai tanggal input pengisian, kolom nik diisi sesuai dengan nik karyawan, setelah kolom nik diisi otomatis kolom name akan terisi dengan sendirinya sesuai dengan nik karyawan. Pengisian judul buku sesuai dengan nama buku yang dibaca dan pengisian halaman sesuai dengan jumlah halaman yang dibaca. Setelah itu klik tombol submit untuk pendistribusian data kedalam database. kitabikinin.com

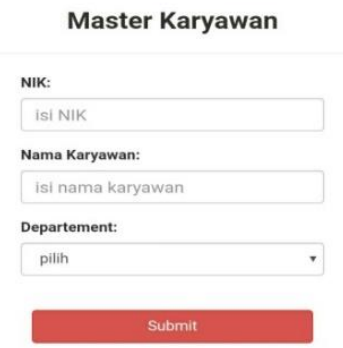

Gambar 4.15 Halaman Master Karyawan

master karyawan untuk mengumpulkan setiap data karyawan. terdapat 3 kolom, dengan kolom nama diisi sesuai dengan nama karyawan, kolom nik diisi sesuai dengan nomor induk karyawan, kolom dept. diisi sesuai dengan departemen karyawan. Tombol submit digunakan untuk mendistribusikan hasil input data ke dalam database.

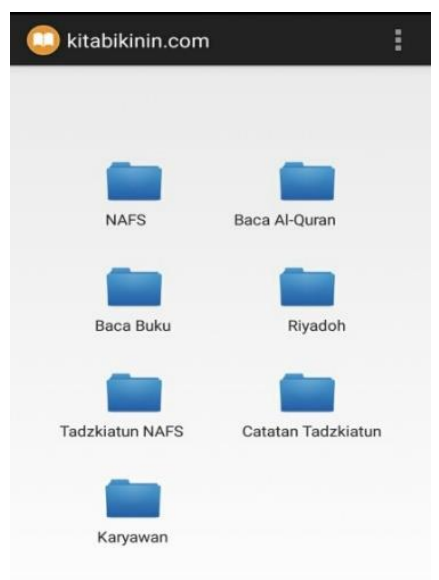

Gambar 4.16 Halaman View

Dalam menu view berisikan output keseluruhan dari inputan menu utama. Menu riyadoh berisikan output dari menu riyadoh pada menu utama, menu baca Al-Quran berisikan output dari menu baca Al-Quran pada menu utama, menu baca buku berisikan output dari menu baca buku pada menu utama, menu catatan tadzkiah berisikan output dari menu tadzkiah nafs pada menu utama, menu nafs berisikan keseluruhan total dari perhitungan riyadoh, tadzkiatun nafs, dan catatan tadzkiatun, untuk menu karyawan berisikan identitas karyawan. 


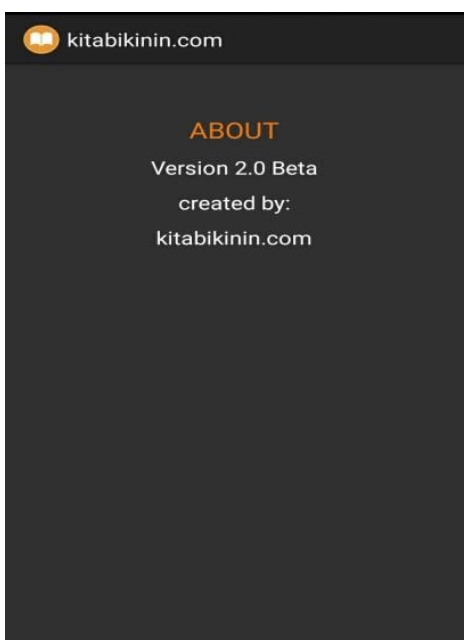

Gambar 4.17 Halaman About

tampilan berisi penggunaan aplikasi yang dijadikan pointpoint untuk pengarahan karyawan dalam melakukan input dan melihat hasil output. Versi 2.0 merupakan versi kedua selesainya aplikasi android.
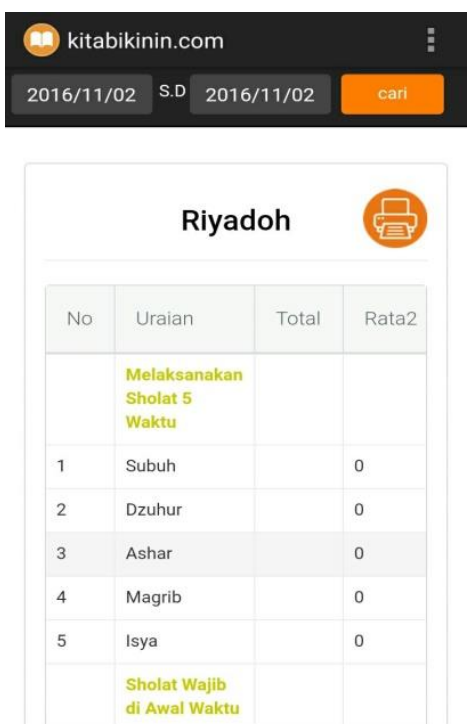

Gambar 4.18 Halaman View Riyadoh

Merupakan output yang hanya berisikan hasil dari input riyadoh pada menu utama. Pada kolom tanggal untuk pengisian tanggal yang ingin dilihat atau diambil datanya. Kolom option untuk meminimalkan field data agar memudahkan dalam pencarian. Kolom search digunakan untuk pencarian nama karyawan secara lebih detail. Dan icon print, untuk export data kedalam bentuk pdf.
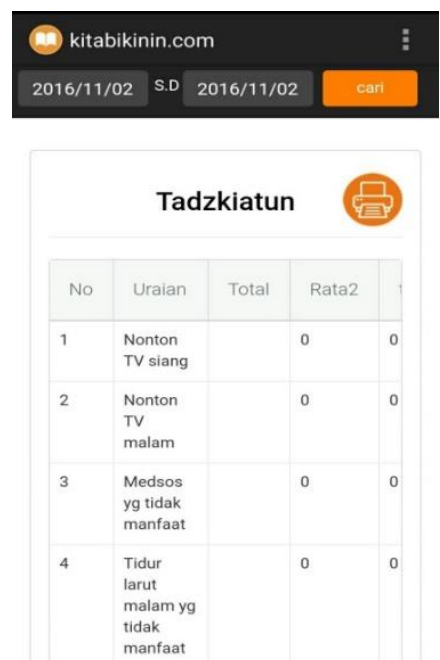

Gambar 4.19 Halaman View Tadzkiatun

Merupakan output yang hanya berisikan hasil dari input tadzkiatun pada menu utama. Pada kolom tanggal untuk pengisian tanggal yang ingin dilihat atau diambil datanya. Kolom option untuk meminimalkan field data agar memudahkan dalam pencarian. Kolom search digunakan untuk pencarian nama karyawan secara lebih detail. Dan icon print, untuk export data kedalam bentuk pdf.
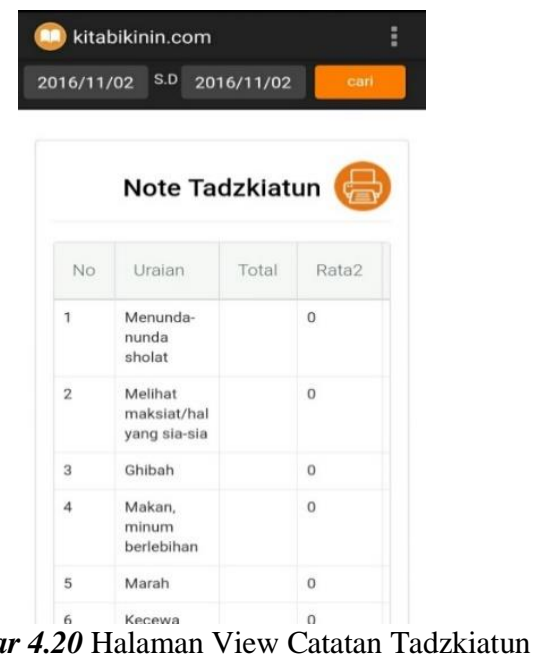

Gambar 4.20 Halaman View Catatan Tadzkiatun

merupakan output yang hanya berisikan hasil dari input catatan tadzkiatun pada menu utama. Pada kolom tanggal untuk pengisian tanggal yang ingin dilihat atau diambil datanya. Kolom option untuk meminimalkan field data agar memudahkan dalam pencarian. Kolom search digunakan untuk pencarian nama karyawan secara lebih detail. Dan icon print, untuk export data kedalam bentuk pdf. 

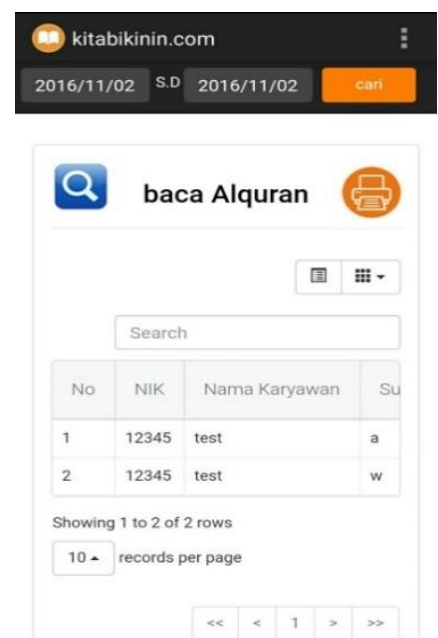

Gambar 4.21 Halaman View Baca Al-Quran

Merupakan output yang hanya berisikan hasil dari input baca Al-Quran pada menu utama. Pada kolom tanggal untuk pengisian tanggal yang ingin dilihat atau diambil datanya. Kolom option untuk meminimalkan field data agar memudahkan dalam pencarian. Icon serach digunakan untuk mencari data karyawan sesuai department dan nama karyawan Kolom search digunakan untuk pencarian nama karyawan secara lebih detail. Dan icon print, untuk export data kedalam bentuk pdf.
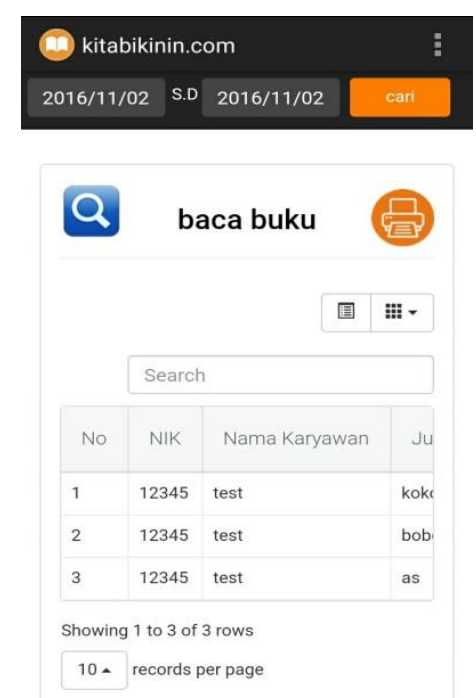

Gambar 4.22 Halaman View Baca Buku

Merupakan output yang hanya berisikan hasil dari input baca buku pada menu utama. Pada kolom tanggal untuk pengisian tanggal yang ingin dilihat atau diambil datanya. Kolom option untuk meminimalkan field data agar memudahkan dalam pencarian. Icon serach digunakan untuk mencari data karyawan sesuai department dan nama karyawan. Kolom search digunakan untuk pencarian nama karyawan secara lebih detail. Dan icon print, untuk export data kedalam bentuk pdf.
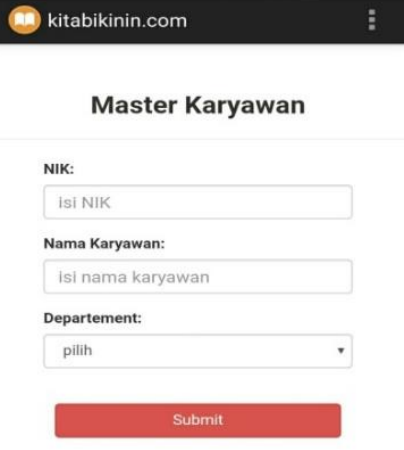

Gambar 4.23 Halaman View Master Karya

Merupakan output yang hanya berisikan hasil dari input master karyawan pada menu utama. Pada kolom tanggal untuk pengisian tanggal yang ingin dilihat atau diambil datanya. Kolom option untuk meminimalkan field data agar memudahkan dalam pencarian. Kolom search digunakan untuk pencarian nama karyawan secara lebih detail. Dan icon print, untuk export data kedalam bentuk pdf.

\section{SIMPULAN}

Aplikasi android bidang personalia Toko Retail Idolmart telah selesai dibuat, dan pengujian sesuai terhadap program penilaian divisi personalia.

\section{Kepustakaan}

[1] Ardy Tri Widiyanto, Sistem pendukung keputusan dalam menentukan karyawan terbaik pada pt. Tembaga mulia semanan dengan metode topsis, Jakarta. (2016).

[2] Taufik, Prima Fithri-Perancangan Aplikasi Sistem Penilaian Kinerja Karyawan Dengan Metode MBO Dan Bars: BPFE. (2014).

[3] Joko Susetyo, Pengukuran Kinerja Dengan Menggunakan Balanced Scorecard Dan Integrated Performance Measurement System (IPMS), A.U.L Sabakula. (2014).

[4] Rivai, Veithzal, Manajemen Sumber Daya Manusia untuk Perusahan: dari Teorike Praktik. Jakarta: PT. Rajagrafindo Persada. (2013).

[5] Sunyoto, Danang, Teori, Kuesioner, dan Analisis Data Sumber Daya Manusia (Praktik Penelitian). Cetakan ke-2. CAPS. Yogyakarta. (2013)

[6] Eka Fachrizal, Abadi Ginting, Penilaian Kinerja Karyawan Dengan Menggunakan Metode 360 Degree Feedback Pada Hotel XYZ Medan. (2013)

[7] Chris Rowley dan Keith Jackson, Manajemen Sumber Daya Manusia. PT. RajaGrafindo Persada, Jakarta. (2012)

[8] Pressman, R.S., ), Software Engineering : a practitioner's approach, McGraw-Hill, New York, 68. (2010)

[9] Ellyta Yullyanti, Analisis Proses Rekrutmen Dan Seleksi Pada Kinerja Pegawai. (2009)

[10] R Heidjrachman, S Husnan - Manajemen Personalia Yogyakarta : BPFE. (2002) 